\title{
REESTRUTURAÇÃO DA GESTÃO DAS VIGILÂNCIAS EM SAÚDE EM ALAGOAS: A PRECARIZAÇÃO DA FORMAÇÃO E DO TRABALHO
}

\author{
RESTRUCTURING HEALTH SURVEILLANCE MANAGEMENT IN ALAGOAS, BRAZIL: PRACARIZATION \\ OF TRAINING AND LABOR
}

REESTRUCTURACIÓN DE LA GESTIÓN DE LAS VIGILANCIAS EN LA SALUD EN ALAGOAS, BRASIL:

LA PRECARIZACIÓN DE LA FORMACIÓN Y DEL TRABAJO

\author{
Tânia Kátia de Araújo Mendes ${ }^{1}$ \\ Sérgio Pacheco de Oliveira ${ }^{2}$ \\ Elizabete Vianna Delamarque ${ }^{3}$ \\ Marismary Horsth De Seta ${ }^{4}$
}

Resumo A descentralização das vigilâncias sanitária, epidemiológica e ambiental para os municípios tomou impulso com mudanças organizacionais e no financiamento federal, quando cresceu a ideia de integração entre elas, e delas com a atenção individual e coletiva. Nos organogramas de muitas secretarias de Saúde, reuniram-se as vigilâncias sob uma coordenação comum, e os gestores demandaram a formação de novos profissionais para esse arranjo. Este artigo objetiva delinear os perfis dos profissionais de nível médio das vigilâncias de seis municípios do estado de Alagoas e dos serviços em que eles operam, agregando percepções dos gestores sobre a prática desses trabalhadores, que representam $88 \%$ da força de trabalho das vigilâncias nesses municípios. Sem formação específica para realizar suas atividades, o desempenho dos trabalhadores foi avaliado como pior quanto menor o tempo de exercício do gestor no cargo. As dificuldades destacadas foram: ingerência política no trabalho da vigilância sanitária e ambiental; preenchimento deficiente das fichas de investigação epidemiológica pelas equipes de saúde da família nos seis municípios; papel indefinido desse profissional na vigilância em saúde do trabalhador. A necessária formação técnica é insuficiente para superação dessas dificuldades, requerendo-se a revisão de processos de gestão e coordenação do trabalho das equipes para práticas mais efetivas.

Palavras-chave educação profissional; vigilância sanitária; vigilância epidemiológica; vigilância ambiental; vigilância em saúde.
Abstract The decentralization of health, epidemiological, and environmental surveillance at municipalities was driven by organizational changes and changes made to federal funding, and the idea of not only integrating them, but also blending them with individual and collective care, gained momentum. Many health departments' organization charts brought the different surveillances together under a common coordination, and managers demanded new professionals be trained to meet the needs of this arrangement. This article aims to outline the profile of the middle-level professionals at the surveillances at six municipalities in the state of Alagoas, Brazil, and services they provide, adding the views of the managers about the practices of these workers, who account for 88 percent of the surveillance workforces in these municipalities. With no specific training to carry their activities out, it was noted that the less time the manager had been holding his or her position, the poorer the employees performed. The main difficulties highlighted were political interference in the health and environmental monitoring work; poor filling in of the epidemiological investigation forms by the family health teams in the six municipalities, in addition to these professionals' undefined roles in worker health surveillance. The required technical training is insufficient to overcome these difficulties, a fact that demands a revision of the teams' labor management and coordination processes to ensure more effective practices.

Keywords professional education; health surveillance; epidemiological surveillance; environmental surveillance; health surveillance. 


\section{Introdução}

No Brasil, as vigilâncias sanitária, epidemiológica, ambiental em saúde e em saúde do trabalhador apresentam distintos graus de desenvolvimento e institucionalização. As duas primeiras têm origens muito anteriores à criação do Sistema Único de Saúde (SUS) e se desenvolveram desigualmente, em diferentes setores do órgão federal de saúde, durante todo o século XX. A vigilância em saúde do trabalhador se instituiu com o próprio SUS, após a Constituição de 1988, e a vigilância ambiental em saúde é ainda mais recente.

A partir dos anos 1970, estruturou-se um Sistema Nacional de Vigilância Epidemiológica, centrado nos serviços correspondentes das esferas federal e estaduais, quando os municípios não se constituíam no terceiro ente do arranjo federativo brasileiro. Fortes mecanismos de coordenação federativa e do trabalho - normas de abrangência nacional e montagem centralizada de bases de dados - proporcionaram o desenvolvimento desse sistema, notadamente nas esferas federal e estadual (De Seta e Dain, 2010). Mas na esfera municipal, à exceção das capitais e dos grandes centros, é possível apostar na persistência de muitas dificuldades na implantação da vigilância epidemiológica (Carvalho et al., 2005). 5

No final dos anos 1990, instituiu-se o Sistema Nacional de Vigilância Sanitária (SNVS), mediante a mesma lei que criou a Agência Nacional de Vigilância Sanitária (Anvisa), responsável por coordená-lo, e esta elegeu a esfera estadual como parceira preferencial na estruturação desse sistema. A incorporação dos municípios ao SNVS, iniciada com os repasses financeiros regulares e automáticos nos anos 2000, pode ser considerada ainda incipiente no que concerne ao controle dos riscos sanitários relacionados ao consumo de produtos, tecnologias e serviços de saúde.

Esse estágio incipiente tem se revelado em estudos (De Seta, 2007; Ferrari, 2010), bem como no recente levantamento sobre a vigilância sanitária nos municípios realizado pela Anvisa (Agência Nacional de Vigilância Sanitária, 2013). Em pouco mais da metade (52\%) dos 3.997 municípios respondentes, há instauração de processo administrativo sanitário. Mas o que chama a atenção é que, em quarenta dos 264 municípios com mais de cem mil habitantes que responderam à pesquisa, tal instauração não ocorre. ${ }^{6}$ Esse achado é importante na medida em que ele pode refletir o grau de organização formal do processo de trabalho das vigilâncias municipais e o uso do poder de polícia administrativa.

Foi na vigência da norma operacional básica do SUS (NOB SUS) 01/96 e dos incentivos financeiros que ela instituiu - que tomou impulso a descentralização das ações das vigilâncias sanitária, epidemiológica e em saúde ambiental para os municípios. Matrizes distintas de financiamento e normatizações específicas balizaram a descentralização da vigilância epidemioló- 
gica e ambiental, que veio a se chamar 'vigilância em saúde', bem como da vigilância sanitária (De Seta e Dain, 2010).

Em 2003, criou-se a Secretaria de Vigilância em Saúde do Ministério da Saúde (SVS/MS), e a Programação Integrada da Epidemiologia e Controle de Doenças passou a se denominar Programação Integrada da Vigilância em Saúde, incluindo, após 2004, algumas ações de vigilância sanitária. Após 2006, os recursos financeiros federais destinados às vigilâncias passaram a compor o bloco de financiamento 'Vigilância em Saúde' (De Seta, 2007). Outras mudanças foram introduzidas, como a incorporação da vigilância em saúde do trabalhador à SVS/MS e a inclusão da vigilância sanitária no conjunto das práticas de vigilância em saúde, por meio da portaria $\mathrm{n}$. 3.252/2009 (Brasil, 2009a), substituída pela portaria n. 1.378/2013 (Brasil, 2013). Ressalte-se que em ambas coexistem dois sistemas nacionais distintos para as vigilâncias: o Sistema Nacional de Vigilância Sanitária e o Sistema Nacional de Vigilância em Saúde (De Seta e Reis, 2011).

Enquanto se produziam essas mudanças, cresceu novamente a ideia de reunir as vigilâncias sob uma coordenação comum em várias secretarias de Saúde de estados e municípios, 7 e diversos gestores demandaram a formação de novos profissionais para trabalhar de acordo com esse modelo.

Em 2008, o Catálogo Nacional de Cursos Técnicos, aprovado pela portaria n. 870, do Gabinete do Ministro da Educação (Brasil, 2008) recomendou que o técnico de vigilância em saúde substituísse uma habilitação profissional existente, o técnico em vigilância sanitária e ambiental (TVSA), curso oferecido na época em algumas escolas técnicas do SUS e atualmente oferecido apenas residualmente. Ressalte-se que, em Alagoas, nenhuma formação técnica de nível médio para as vigilâncias foi oferecida, sendo ofertada para trezentos alunos a qualificação básica em agentes de vigilância em saúde por meio do Programa de Formação de Agentes Locais de Vigilância em Saúde (Proformar). ${ }^{8}$ Um ex-aluno do Proformar integrou a população do estudo e é supervisor de campo no controle de endemias.

Neste artigo, delineiam-se os perfis dos trabalhadores de nível médio das vigilâncias de seis municípios de Alagoas e dos serviços em que eles operam, buscando agregar percepções dos gestores municipais de saúde quanto à participação desses trabalhadores nas práticas das vigilâncias. Os perfis - dos trabalhadores e dos serviços - desenvolvidos para os seis municípios do estado que integraram o estudo apresentam correspondências com achados de estudos realizados em outros estados brasileiros onde se busca implantar, localmente, as quatro vigilâncias do campo da saúde (Ferrari, 2010). 


\section{Escolhas e percurso metodológico}

Tratou-se de estudo de abordagem qualitativa que adotou a entrevista semiestruturada como estratégia, com a elaboração de dois roteiros específicos testados no município de Rio Largo, no estado de Alagoas, não incluído no estudo. Um roteiro, destinado aos trabalhadores de nível médio, incluiu dados sobre o trabalho e as condições em que ele se realiza, e sobre a articulação das ações das vigilâncias entre si e com a atenção básica. O outro, destinado aos gestores, explorou sua percepção sobre o desempenho dos trabalhadores. Ambos os roteiros abordavam as dificuldades e facilidades encontradas.

Para contemplar municípios de diferentes portes, incluiu-se no estudo um município de cada uma das cinco faixas populacionais, procedendo-se a sorteio sempre que havia mais de um município na mesma faixa. Como 63\% dos municípios tinham menos de vinte mil habitantes, incluiu-se um segundo município dessa faixa, totalizando seis municípios no estudo, apresentados na Tabela 1.

Tabela 1

\begin{tabular}{|c|c|c|c|}
\hline Faixa populacional & Número de municípios & Porcentagem & Município participante \\
\hline Acima de 300.001 & 01 & $1 \%$ & Município 1 \\
\hline 100.001 a 300.000 & 01 & $1 \%$ & Município 2 \\
\hline 50.001 a 100.000 & 04 & $4 \%$ & Município 3 \\
\hline 20.001 a 50.000 & 32 & $31 \%$ & Município 4 \\
\hline Até 20.000 & 64 & $63 \%$ & Município 5* e Município 6 \\
\hline
\end{tabular}

As entrevistas, com trabalhadores de nível médio indicados pelos coordenadores da Vigilância em Saúde, gestores ou coordenadores das vigilâncias em saúde e gerentes do Centro de Referência em Saúde do Trabalhador (Cerest), foram gravadas e depois transcritas. Classificaram-se as respostas por área de prática e entrecruzaram-se os dados que expressavam o cotidiano dos trabalhadores e o pensamento dos gestores. Em cada categoria temática, correspondente a cada área de prática, analisaram-se: estruturação dos serviços; perfil e atribuições dos trabalhadores; e dificuldades no trabalho.

A pesquisa foi aprovada pelo Comitê de Ética em Pesquisa (CEP) da Escola Nacional de Saúde Pública Sergio Arouca da Fundação Oswaldo Cruz (Ensp/Fiocruz), por meio do parecer n. 0094.0.000-09. 


\section{Os entrevistados e a situação distinta do trabalhador de nível médio na Saúde do Trabalhador}

Realizaram-se 22 entrevistas, sendo abrangidos 14 trabalhadores de nível médio das vigilâncias epidemiológica, sanitária e ambiental, ressaltando-se que, em quatro municípios, o mesmo trabalhador da vigilância sanitária assumia também a ambiental. Foram entrevistados, ainda, gestores municipais e quatro coordenadores das vigilâncias do campo da saúde, indicados por seus gestores para representá-los, e da saúde do trabalhador. Na Tabela 2, é apresentada a distribuição dos entrevistados por segmento profissional e por município.

Tabela 2

Total de entrevistados por segmento e município

\begin{tabular}{|c|c|c|c|c|c|}
\hline Municípios & $\begin{array}{c}\text { Trabalhadores de } \\
\text { nível médio }\end{array}$ & Gestores & $\begin{array}{c}\text { Coordenadores das } \\
\text { vigilâncias }\end{array}$ & $\begin{array}{c}\text { Gerentes da saúde } \\
\text { do trabalhador }\end{array}$ & $\begin{array}{l}\text { Total por } \\
\text { município }\end{array}$ \\
\hline Município 1 & 03 & - & 01 & $01 *$ & $01 *$ \\
\hline Município 2 & 02 & - & 01 & $01 * *$ & $01 * *$ \\
\hline Município 3 & 03 & - & 01 & - & - \\
\hline Município 4 & 02 & - & 01 & - & - \\
\hline Município 5 & 02 & 01 & - & - & - \\
\hline Município 6 & 02 & 01 & - & - & - \\
\hline Total & 14 & 02 & 04 & 02 & 02 \\
\hline
\end{tabular}

Fonte: Estudo elaborado pelos autores.

*Servidor do estado de Alagoas.

** Servidor do Cerest regional do município 2.

Em razão do estágio inicial de funcionamento da vigilância em saúde do trabalhador e na impossibilidade de se encontrar o trabalhador de nível médio dessa área de prática no campo, entrevistaram-se dois gerentes, um da esfera estadual e outro da municipal, ambos dos Centros de Referência em Saúde do Trabalhador (Cerests), sendo o da esfera municipal o do município 2.

Os Cerests dos municípios 1 e 2 têm abrangência regional. Dentre os municípios do estudo, o primeiro cobre também o município 3. Os demais municípios do estudo - municípios 4 , 5 e 6 - são cobertos pelo Cerest do município 1. Os municípios 1, 2, 3 e 6 integram a rede sentinela de notificação de agravos em saúde do trabalhador em Alagoas.

Nos seis municípios pesquisados, foram encontrados apenas quatro trabalhadores de nível médio em cada um dos Cerests dos municípios 1 e 2, o que poderia demonstrar alguma coerência com os parâmetros contidos na 
portaria n. 2.437/2005 (Brasil, 2005), da Rede Nacional da Saúde do Trabalhador (Renast), não mais vigente. Essa norma foi substituída pela portaria n. 2.728/2009 (Brasil, 2009b), que não mais apresenta parâmetros de dotação de recursos humanos para o Cerest.

Leão e Castro (2013, p. 770) afirmam que, do ponto de vista da pesquisa, “o estudo objetivo dos Cerests e da Renast ainda não mobiliza muitos pesquisadores". Das análises publicadas, duas se basearam em dados coletados até 2009. Referindo-se ao nível do país, a primeira aponta que a vigilância em saúde do trabalhador em Alagoas não recebia aportes financeiros das esferas estadual e municipal como contrapartida aos recursos federais repassados para a implementação dessa política (Machado et al., 2013). A segunda análise aponta que a implantação dos Cerests no estado de Alagoas se encontrava em estágio intermediário quanto a infraestrutura, gestão e organização dos serviços, e no desenvolvimento das ações previstas de vigilância à saúde do trabalhador; no entanto, estava em estágio incipiente para o nível de implantação de ações específicas de notificação, como organização dos dados, análise e interpretação (Galdino, Santana e Ferrite, 2012).

Os coordenadores de vigilância em saúde do trabalhador apontaram que os trabalhadores de nível médio executavam atividades administrativas no arquivo ou no almoxarifado, ou nos setores de informação, alimentando o Sistema de Informações de Agravos de Notificação (Sinan), possivelmente sua atividade mais próxima da área finalística. A busca ativa aos casos de doenças advindas do trabalho e aos acidentados do trabalho deveria ser executada, segundo eles, por agentes comunitários de saúde (ACSs) que seriam treinados. Isso pode ser atribuído à concepção predominante naquela época sobre a necessidade de integração com a atenção básica, preconizada pela portaria n. 3.252/2009 (Brasil, 2009a), então vigente. A diversidade de atividades, algumas de cunho claramente administrativo, parece indicar indefinição, certa falta de clareza acerca do papel do trabalhador de nível médio na vigilância em saúde do trabalhador, situação diversa da que foi encontrada para o papel dos trabalhadores de nível médio nas demais vigilâncias.

Apresentam-se os demais resultados agrupados em: estruturação das vigilâncias municipais; os trabalhadores de nível médio das vigilâncias; o que fazem os trabalhadores nas vigilâncias epidemiológica, sanitária e ambiental; articulações entre os trabalhadores das vigilâncias e principais dificuldades referidas.

\section{Estruturação das vigilâncias municipais}

Os seis municípios do estudo encontram-se entre os 19 do estado considerados prioritários para dengue, o que pode contribuir para um contingente 
maior de trabalhadores na Vigilância Ambiental em relação às outras áreas de prática em alguns municípios estudados. Outra característica comum é que nos novos organogramas das secretarias municipais de Saúde (SMSs) nenhum deles fora ainda aprovado pela Câmara Municipal no momento da coleta de dados - consta o setor de vigilância em saúde, embora nos municípios 5 e 6 não existissem os respectivos coordenadores.

A mudança na denominação dos serviços de vigilância sanitária, ou a criação de mais um nível hierárquico para a coordenação das vigilâncias, tem se revelado em outros estudos (Ferrari, 2010). Esse mimetismo organizacional, praticado como estratégia para recebimento de recursos financeiros e cooperação técnica da esfera de governo mais abrangente, era esperado após a criação da SVS/MS e com a instituição do bloco de financiamento 'Vigilância em Saúde' (De Seta e Dain, 2010; De Seta, 2007; Abrucio, 1998).

Nos municípios 1 e 2, a coordenação da vigilância em saúde funcionava em espaço físico específico, e as coordenações de cada uma das vigilâncias dispunham de telefone e computador conectado à internet e de uso exclusivo; no entanto, nos setores que operacionalizam as ações, só existia linha telefônica.

Os entrevistados informaram executar toda a gama de atividades do escopo da vigilância em saúde, que agrega também a vigilância sanitária e a vigilância em saúde do trabalhador. Contudo, esta última se encontrava mais estruturada nos municípios 1 e 2, representantes das faixas mais populosas de Alagoas no estudo. Ademais, das ações propostas para a vigilância ambiental em saúde, somente a coleta da água para análise se realizava, em razão da pactuação com o estado, e essa atividade era executada em todos os municípios por trabalhadores da vigilância sanitária treinados para tal.

Não se demonstrou insatisfação com o Laboratório Central do Estado (Lacen), apesar de, em quatro municípios, ser apontada falta ocasional de material para análise microbiológica da água. Nos municípios 1, 2 e 3, existiam laboratórios municipais para análise da água; nos dois primeiros, existiam centros de controle de zoonoses (CCZs), responsáveis pelo controle das endemias, com laboratório próprio. Nos demais municípios, o controle de endemias estava subordinado à coordenação de vigilância epidemiológica.

Apenas no município 4 se referiu não haver dificuldade de transporte para as vigilâncias. Em todos os municípios, o setor com melhores condições de trabalho é o de combate à dengue. Para as demais endemias, identificaram-se muitas dificuldades operacionais.

Alguns achados da pesquisa foram comuns. Em primeiro lugar, apesar da importância atribuída ao Código Sanitário para ancorar a ação da vigilância sanitária, todos os trabalhadores referiram sua desatualização. Em segundo, apesar de não constar no roteiro nenhuma pergunta sobre o tema, em todos os municípios, exceto no município 1 , os trabalhadores se queixaram de ingerência política no trabalho nas vigilâncias sanitária e ambiental, e informaram 
que ela ocorre nos atos praticados pelos trabalhadores de nível médio e de nível superior. Todos os trabalhadores elogiaram o apoio recebido da Coordenação Estadual de Vigilância Sanitária e da Vigilância Ambiental. Em todos os municípios, pelo menos um trabalhador manifestou que havia muita pressão para o cumprimento das metas pactuadas com o estado. Nos seis municípios, as ações de vigilância epidemiológica estavam descentralizadas para as unidades de saúde da família, embora persistissem dificuldades, principalmente no preenchimento das fichas de investigação.

Nos três maiores municípios, os trabalhadores de vigilância sanitária tinham atribuições específicas e fiscalizavam alimentos, medicamentos ou serviços de interesse da saúde. Essa especialização ocorria em diversos serviços estaduais e nos municípios maiores e nas capitais, parecendo refletir o aumento do número de estabelecimentos sujeitos à vigilância sanitária, que acompanha a maior concentração populacional.

Nos municípios 4 e 6 não havia essa especialização, e os trabalhadores conheciam melhor as atividades das outras equipes. Contudo, informaram não terem autonomia para exercer plenamente as ações da vigilância sanitária e solicitar apoio da equipe estadual, achado semelhante ao encontrado em estudo sobre as ações de fiscalização em Mato Grosso, na região de Sinop (Ferrari, 2010).

O município 5 era o único do estudo que não emitia alvará sanitário. Porém, dos cinco que o faziam, só três (municípios 1, 3 e 4) cobravam taxas de vigilância sanitária. A aplicação de multas, quando há infração ao Código Sanitário Municipal, se restringia aos municípios 1 e 4.

Em três municípios (2, 3 e 4), os trabalhadores da vigilância sanitária afirmaram que, no contexto geral, as outras equipes da SMS tinham a primazia no uso do transporte, e o trabalho da vigilância sanitária era visto como menos importante.

A distribuição dos trabalhadores de nível médio, informada pelas respectivas secretarias, pode ser vista na Tabela 3.

Tabela 3

Distribuição dos trabalhadores de nível médio nas vigilâncias - municípios do estudo

\begin{tabular}{|c|c|c|c|c|c|c|}
\hline Município 1 & 39 & 121 & 902 & 04 & - & 1.066 \\
\hline Município 2 & 18 & 28 & - & 04 & 140 & 190 \\
\hline Município 5 & 02 & 11 & - & - & - & 13 \\
\hline Município 6 & 04 & 18 & - & - & - & 22 \\
\hline TOTAL & 80 & 277 & 902 & 08 & 140 & 1.407 \\
\hline
\end{tabular}

Fonte: Estudo elaborado pelos autores. 
As vigilâncias dos municípios 1, 2 e 3 tinham maior quantitativo de trabalhadores de nível médio. Os trabalhadores da vigilância sanitária do município 1 representavam apenas $3,7 \%$ da força de trabalho das vigilâncias, enquanto os do município $6,9,1 \%$; os do município $2,9,5 \%$; os do município 4, 13,3\%; os do município 5, 15,4\%; e os do município 3, 15,4\%.

Contudo, o que chamou a atenção nos dados apresentados na Tabela 3 foi o expressivo quantitativo de pessoal de nível médio lotado na vigilância ambiental do município l. É certo que não existe parâmetro consensual que estabeleça proporcionalidade entre população e equipe de saúde pública, ou entre as equipes das vigilâncias, e que esse é o município mais populoso do estudo. Segundo o coordenador da vigilância em saúde desse município, os trabalhadores do controle de endemias que ficavam lotados no Centro de Controle de Zoonoses foram apresentados compondo a vigilância ambiental, na medida em que:

Com a aprovação do organograma que estará sendo apresentado à Câmara Municipal, a vigilância ambiental passará a ter seu espaço próprio e deverá agregar as ações de controle dos riscos biológicos e não biológicos, porque atualmente está uma coisa de um lado e outra coisa de outro, acho isso muito errado (coordenador da vigilância em saúde, ex-coordenador do CCZ, há dois anos na função).

\section{Os trabalhadores de nível médio das vigilâncias}

Esses trabalhadores recebem diversas denominações. Na vigilância sanitária, são conhecidos como: agente sanitarista; auxiliar sanitário; fiscal sanitário; auxiliar administrativo de vigilância sanitária e inspetor de saneamento. $\mathrm{Na}$ vigilância epidemiológica: agente de vigilância epidemiológica; agente comunitário de endemias, agente de endemias; agente de saúde pública e guarda de endemias. Na vigilância ambiental, embora exista o agente de vigilância ambiental, essas ações são realizadas pela vigilância sanitária. Trabalhadores que executam as mesmas ações - a depender do tempo da contratação - no mesmo município recebem denominações distintas, o que pode gerar falta de identidade profissional.

Nos municípios estudados, os trabalhadores de nível médio representaram, em média, $88 \%$ da força de trabalho das vigilâncias, conforme disposto na Tabela 4 . 
Tabela 4

\begin{tabular}{lcccc}
\hline \multicolumn{5}{l}{$\begin{array}{l}\text { Percentual de representatividade dos trabalhadores de nível médio na composição } \\
\text { da força de trabalho das vigilâncias nos }\end{array}$ micípios estudados, 2009 } \\
\hline Municípios & Nível superior & Nível médio & Total & Nível médio (\%) \\
\hline Município 1 & 120 & 1.068 & 1.188 & $90 \%$ \\
Município 2 & 47 & 190 & 237 & $80 \%$ \\
Município 3 & 9 & 82 & 91 & $90 \%$ \\
Município 4 & 5 & 45 & 50 & $90 \%$ \\
Município 5 & 3 & 15 & 18 & $83 \%$ \\
Município 6 & 3 & 12 & 15 & $80 \%$ \\
Total & 187 & 1.412 & 1.599 & $88 \%$ \\
\hline
\end{tabular}

Fonte: Produção própria, com base nos dados recolhidos nos municípios.

Nenhum trabalhador de nível médio tinha formação específica. Alguns receberam treinamentos pontuais ao longo dos anos, importantes por terem proporcionado a introdução ou a produção de ações. Dois entrevistados informaram nunca terem participado de capacitação. Um dos entrevistados (fiscal sanitário, seis meses na função) ressaltou, sobre os treinamentos realizados: "É bom, mas falam de coisas que o município não faz." Tal depoimento sugere a necessidade de melhor articulação entre educação e trabalho.

Não existia uma habilitação técnica para os trabalhadores das vigilâncias epidemiológica e ambiental; para os da vigilância sanitária, a habilitação profissional de nível técnico, a de técnico de vigilância sanitária e ambiental, nunca foi ofertada em Alagoas. Supunha-se, inicialmente, que existiria número expressivo de trabalhadores apenas com ensino fundamental $(6 \%)$, mas $94 \%$ dos trabalhadores têm o ensino médio.

Exceto nos municípios de maior porte, os profissionais de nível superior, contratados para assumir a coordenação das vigilâncias, apresentaram importante rotatividade e, com frequência, não estavam todos os dias no município. Muitas vezes eles definiam atribuições e deixavam orientações para a realização de atividades, o que pode configurar, para os trabalhadores de nível médio, uma prática subordinada e pouco reflexiva.

Os trabalhadores de nível médio (75\%) tinham mais de dez anos de serviço, enquanto $25 \%$ trabalhavam entre cinco e nove anos, não se percebendo rotatividade. Somente no município 1 existiam trabalhadores precarizados, com oito anos de serviço na vigilância epidemiológica e sanitária. Nos demais municípios, os trabalhadores de nível médio adquiriram estabilidade por tempo de serviço ou por aprovação em concurso público.

Os gestores entrevistados indicaram ser necessário capacitar os trabalhadores das vigilâncias, pois estes representam um contingente expressivo num campo estratégico da política de saúde. 
No organograma do município 2, o CCZ não integrava a estrutura de nenhuma das vigilâncias, mas representava uma coordenação específica na vigilância em saúde.

\section{O que fazem os trabalhadores na vigilância sanitária}

No município 1, o trabalhador de nível médio colaborava em todo o trabalho de campo, acompanhando o nível superior durante as inspeções de alimentos e medicamentos, mas nunca assinava os autos. Quanto às inspeções em hospitais de média e alta complexidades, as ações da vigilância sanitária eram realizadas por equipe de nível superior multidisciplinar.

Nos municípios 2 e 3, o trabalhador de nível médio inspecionava alimentos e saneantes de forma autônoma, inclusive assinando os autos emitidos. Em relação aos demais setores, esse profissional acompanhava e auxiliava durante as inspeções; no entanto, a responsabilidade em assinar os autos era dos profissionais de nível superior.

Segundo os trabalhadores, a vigilância sanitária realiza as seguintes atividades: atendimento aos reclamos da população sobre o esgotamento de águas servidas, acúmulo de lixo nos logradouros, criadouros de galinhas e porcos no perímetro urbano e armazenamento de ferro velho em áreas inadequadas; inspeção sanitária e de rotina; cadastramento de estabelecimentos; concessão de licença sanitária (apenas um município não licencia); notificação de irregularidades; recolhimento de alimentos, medicamentos e outras mercadorias; interdição de estabelecimentos; aplicação de multas aos infratores do Código Sanitário (em dois municípios); participação em campanhas de vacinação antirrábica, além de atividades educativas no ato das inspeções.

Os trabalhadores foram unânimes em afirmar que as orientações individualizadas, no ato da inspeção, são a melhor forma de se fazer educação em saúde, porque se aborda diretamente o problema. Quando interrogados se desenvolviam ações coletivas, grupais, de educação em saúde, um fiscal sanitário argumentou que eles não as faziam porque

atrapalharia as atividades de campo, porque se precisa atender às reclamações e fazer inspeção em um grande número de estabelecimentos de acordo com a programação que a coordenadora da Visa faz para a semana (fiscal sanitário, 15 anos na função).

Trabalhadores de quatro municípios informaram existir o setor de Promoção da Saúde. Segundo dois deles: “os técnicos desse setor é que deveriam estar realizando rotineiramente as ações coletivas de educação e outras formas de mobilização; eles não são da promoção da saúde?" (fiscal sanitário 
e ambiental, dez anos na função); e "educação em saúde é uma responsabilidade do pessoal da promoção da saúde" (agente sanitário, dez anos na função).

Esses trabalhadores consideraram que a ação de educação em saúde é feita 'para' a população e não 'junto com' a população. Tal percepção, possivelmente, decorreu das atividades pedagógicas costumeiras, nas quais uns detêm o conhecimento e ensinam aos que 'não sabem'. Então eles depreendem que têm que saber muito e, por serem sujeitos sociais inseridos nesse contexto, reproduzem essa cultura. Reforça-se, portanto, a importância de processos inovadores de qualificação e formação desses trabalhadores.

Quanto à parceria com outros setores, identificaram-se variações, a depender da estruturação administrativa de cada município:

Aqui, problemas como: esgotamento sanitário acumulado nas vias públicas causando situações incômodas para algumas residências; depósitos de ferro velho sem proteção e inadequadamente armazenado juntando roedores; fossas cheias e com vazamento... essas coisas nós procuramos resolver encaminhando para a Secretaria de Obras. Já problemas de recolhimento do lixo, ou campanhas de limpeza urbana, a gente pede ajuda ao Setor de Limpeza Urbana da Prefeitura (fiscal sanitário, vinte anos na função).

Nos municípios 5 e 6, essas secretarias não estavam estruturadas, e se informou que são acionados os setores administrativos das prefeituras e o responsável pela limpeza urbana. Sobre essa questão, pareceu que muitas vezes, diante da situação encontrada pelos trabalhadores, estes procediam como sendo o problema uma responsabilidade que 'ele' deveria assumir e ele 'individualmente' deveria procurar as autoridades competentes. Transpareceu que, ao passarem a responsabilidade para estas resolverem, sua missão estaria cumprida. Nos municípios maiores, eles repassavam para o coordenador da vigilância em saúde, que encaminhava às autoridades competentes.

Apenas um dos entrevistados afirmou, com segurança, que quando solicitava ajuda ao administrador da Prefeitura o problema era resolvido. Os demais não informaram o percentual de problemas que era resolvido, e dois pensavam que "como a reclamação não acontece mais, é porque o problema foi resolvido" (fiscal sanitário, cinco anos na função; e o outro, inspetor de saneamento, vinte anos na função).

Essa realidade, expressa com naturalidade pelos entrevistados, sinaliza que o trabalhador não conhece todo o processo de trabalho porque desconhece o produto final, e confirma o anteriormente dito: o trabalhador de nível médio cumpre as tarefas prescritas. Está submisso, pronto para executar o que for pensado e determinado por alguém. Ele faz, anota na sua produção e considera finalizada sua parte. 
De Seta, Reis e Pepe (2011) referem que a capacidade das vigilâncias é condicionada pelo conceito de risco adotado e pela capacidade do serviço, de seu grau de institucionalidade e de sua articulação com as demais ações e instâncias do sistema de saúde e fora dele. Esses fatos devem sinalizar, para a gestão da educação e do trabalho, a necessidade de se investir na qualificação desses trabalhadores, mas também de repensar as práticas da gestão (De Seta, Reis e Pepe, 2011).

\section{O que fazem os trabalhadores na vigilância epidemiológica}

Aqui as atividades são divididas entre os trabalhadores que são dos setores de vigilância epidemiológica das sedes das SMSs e aqueles que realizam as atividades de campo. Em algumas falas dos sujeitos, subliminarmente, percebeu-se que sair do trabalho de campo e ir para a sede da SMS seria adquirir status profissional.

As atividades dos trabalhadores da sede das SMSs na vigilância epidemiológica abrangem: recolhimento semanal das notificações e investigações epidemiológicas nas áreas descobertas pela Estratégia Saúde da Família (ESF); preenchimento de campos das fichas de investigação não preenchidos completamente pelo pessoal das equipes de saúde da família (atividade de campo); participação na organização das campanhas, bloqueios vacinais, distribuição de vacinas para as unidades de saúde da família e recolhimento de material coletado (baciloscopias e sorologias); busca aos faltosos (vacina antirrábica humana, programas de tuberculose e hanseníase, puérperas e recém-nascidos com sífilis não tratada nas áreas descobertas pela ESF); e digitação de dados nos sistemas de informação. Alguns entrevistados informaram participar da análise de dados, mas essa função teria ficado sob a responsabilidade das coordenações da vigilância epidemiológica.

Os trabalhadores de campo das endemias externaram que nem sempre todas as ações são realizadas, em decorrência do número insuficiente de trabalhadores e da falta de insumos básicos, exceto para a dengue, em alguns municípios. Essas ações abrangiam: mapeamento da área por quarteirão e por rua; visitação diária de 28 a 31 domicílios por dia, também para tratamento de focos do mosquito Aedes (devem fazer seis ciclos por ano, o que na maioria das vezes não tem sido possível); reunião semanal para entregar a produção e avaliar o que foi realizado; auxílio no transporte nas campanhas de vacinação; reorganização das atividades de acordo com necessidades de mudança de estratégia. E ainda realizar a busca a caramujos (geralmente em beiras de cacimbas de rios e riachos), que encaminhavam ao laboratório para verificar se estão contaminados; nos domicílios, distribuir coletores de 
fezes, que encaminhavam ao laboratório para análise e, de posse dos resultados, os encaminhavam ao médico das unidades de saúde, retornando para verificar se o tratamento se realizou; visitar os domicílios à procura de cachorros suspeitos, barbeiros e flebótomos, encaminhando os achados ao laboratório para verificar se estão infectados; e em situações de calamidade, a exemplo do período das chuvas, fazer busca de focos de ratos e colocar raticidas.

Percebeu-se, nas falas de alguns guardas ou agentes de endemias, um sentimento de rivalidade para com os ACSs, segundo eles, um profissional “mais destacado" no sistema de saúde: "para os agentes comunitários de saúde, já tem até curso técnico" (agente de endemias, sete anos na função).

Na vigilância epidemiológica do município l, os agentes de vigilância epidemiológica foram distribuídos nos sete distritos sanitários, e em cada um eles respondiam por uma ou duas unidades da ESF (para recolherem as notificações semanais). Nas outras áreas não cobertas pela Saúde da Família, desenvolviam as ações demandadas pelas unidades notificantes e iam a campo mediante programação semanal da Coordenação de Epidemiologia dos distritos sanitários.

\section{O que fazem os trabalhadores na vigilância ambiental}

Conforme se afirmou no item "Estruturação das vigilâncias municipais", das ações propostas para a vigilância ambiental em saúde somente a coleta da água para análise se realizava por pactuação com a esfera estadual no momento da pesquisa. E em quatro dos seis municípios do estudo, os trabalhadores da vigilância sanitária acumulavam a vigilância ambiental.

Destaca-se que, por vezes, a vigilância ambiental era mais facilmente assumida do que a própria ação de vigilância sanitária. Cita-se como exemplo o município 5, onde o profissional da vigilância sanitária assumia a coleta semanal de água, seguida de envio ao Lacen. Mas para outras ações, a exemplo da liberação de alvará de funcionamento, solicitava-se o apoio da vigilância sanitária estadual.

O planejamento das coletas da água variou bastante entre os municípios. No município 6, somente se colhia a água das cacimbas e dos poços artesianos porque se entendia que a Companhia de Abastecimento de Água de Alagoas (Casal) e o Serviço de Abastecimento de Água e Esgoto (Saae) são órgãos do Estado e devem realizar seu próprio monitoramento. Em outros dois municípios se colhia água também do sistema oficial, para monitorar a qualidade e solicitar, quando necessário, a adequação na dosagem do cloro, o que foi exemplificado por um fiscal sanitário:

Eu procuro a Casal e cobro que eles aumentem a dosagem de cloro. Às vezes, eles não colocam o valor recomendado, e quando a água chega nas comunidades mais 
distantes, o cloro já está muito fraco. Quando falo, eles sempre me atendem (fiscal sanitário, 12 anos na função).

Expressam-se situações distintas, uma em relação à rede informal de abastecimento (cacimbas, poços) e a outra em relação ao sistema oficial. É um exemplo claro dos diferentes contextos em que se inserem as práticas desses trabalhadores.

\section{Articulação entre os trabalhadores das vigilâncias}

Sobre a articulação entre os trabalhadores das vigilâncias e a coordenação do trabalho, constatou-se que, de forma geral, não era rotineiro se encontrarem para discutir sobre atividades, e seus contatos objetivavam resolver situações pontuais. Ao serem interrogados se participavam de reunião, um deles expressou:

Não tem reunião com a gente, não, isso é muito raro. Eu acho isso normal. Geralmente nosso coordenador é quem é chamado. Quando tem reunião com a gente, já se sabe que lá vem bronca (agente de vigilância epidemiológica, dez anos na função).

Com referência à articulação com a gestão municipal de saúde, registrou-se o seguinte relato:

Eu gostaria que antes dos festejos, que são muitos aqui no município, fossem realizadas reuniões com todos os barraqueiros, para definição e esclarecimentos de assuntos da Visa, pois é muito mais fácil fazer antes. Eu mando ofício solicitando isso, mas nunca chamam a gente para participar no período anterior aos eventos. Quando chega no dia, nos deparamos com muita coisa errada que poderia ser esclarecida antes, até mesmo com a Prefeitura. Exemplo disso é o tipo de fardamento que mandam fazer sem atender às normas, a exemplo de camisa sem mangas, e muitos descuidos sobre cuidados básicos de higiene (fiscal sanitária, oito anos na função).

Depreende-se dessas falas que é muito prejudicial à organização do processo de trabalho em saúde a inexistência de uma rotina institucional e sistemática de encontros e de grupos de discussão para aproximar as diversas equipes, para criar uma nova forma de relação no trabalho e coordená-lo. Contudo, a maior parte dos entrevistados (75\%) afirmou que, em face da necessidade de resolver problemas, procurava ajuda com os colegas da própria vigilância, e algumas vezes as equipes de atenção básica eram também ao mesmo tempo procuradas por eles. 
A necessidade de articulação entre as equipes é tanto maior quanto mais setorizada é a organização das vigilâncias, o que é frequente nos maiores centros urbanos: vigilância epidemiológica, atenção à saúde do trabalhador, controle de zoonoses ou o serviço de vigilância ambiental. Quando esses setores, mesmo organizados e gerenciados separadamente, mantêm comunicação direta e realizam ações integradas, os resultados são excelentes.

No município 4 havia um trabalho setorizado e relativamente estruturado em cada vigilância. Contudo, especificamente em relação à vigilância sanitária, a distância entre as demais ações de saúde e as das outras coordenações da Secretaria Municipal de Saúde era muito acentuada. Quando inquiridos sobre quais trabalhadores da atenção básica mais procuravam as vigilâncias, disseram ser os ACSs, seguidos dos enfermeiros da ESF.

Sobre os motivos que mais levavam os trabalhadores das vigilâncias a se articularem no dia a dia com a atenção básica, foram registrados os seguintes: solicitação para coleta de água nas áreas quando há aumento de casos de diarreia notificados pelos ACSs; recolhimento de material coletado (para citologia, sorologia, baciloscopia) e encaminhamento ao laboratório; providências quanto a medicamentos para os tratamentos padronizados; pacientes faltosos de tuberculose, hanseníase, sífilis congênita e esquema de vacina atrasado; necessidade de preenchimento de fichas de investigação epidemiológica, as quais na maioria das vezes vêm das unidades de saúde da família com dados faltantes; realização conjunta de palestras sobre doenças endêmicas na região; e participação em campanhas de vacinação.

Reforça-se que aqui também não houve nenhum relato de planejamento ou avaliação institucional conjunta entre as diversas equipes. São acordos pessoais, encarados com naturalidade entre os trabalhadores.

Ao serem investigados sobre as ações intersetoriais, todos os entrevistados consideram que existe articulação intersetorial, pois existe solicitação para que outros setores resolvam problemas que envolvem a saúde.

Nenhum trabalhador referiu envolvimento das vigilâncias com a coordenação de promoção da saúde. Constatou-se que muitos dos entrevistados entendiam promoção da saúde como sinônimo de ações educativas, pelas quais a equipe da promoção da saúde seria responsável. Boa parte da confusão entre promoção e prevenção advém da grande ênfase em modificações de comportamento individual e do foco quase exclusivo na redução de fatores de riscos para determinadas doenças, vigentes em certos programas (Czeresnia, 2003).

\section{Principais dificuldades referidas}

Um novo modelo de gestão no SUS deve possibilitar a satisfação dos trabalhadores nas suas atividades laborais, a diminuição da rotatividade, o aprofun- 
damento da gestão na dimensão do microprocesso de trabalho, a educação permanente e o reconhecimento das mesas de negociação como espaço democrático de equacionamento dos conflitos nas relações do cotidiano. As dificuldades referidas sinalizam quão longe da realidade vivida pelos sujeitos do estudo está esse novo modelo.

Os trabalhadores da vigilância sanitária e ambiental foram unânimes em informar que se sentem pouco valorizados como profissionais. A maioria $(83 \%)$ discorreu sobre as dificuldades de cumprir as rotinas de inspeção em razão, especialmente, do elevado número de estabelecimentos e serviços do setor regulado. Eles disseram que o quantitativo de pessoal não é suficiente para o desenvolvimento das atividades (25\%); demonstraram não possuir respaldo político ao adotarem medidas punitivas (50\%); e sentiram-se marginalizados no que diz respeito aos processos de capacitação (75\%).

Com relação à estrutura de trabalho, 50\% apontaram as acomodações como inadequadas, $25 \%$ informaram falta de computadores conectados à internet e $63 \%$ disseram que há ingerências políticas no trabalho da vigilância sanitária e da vigilância ambiental. Tal ingerência pode ser observada no depoimento do fiscal sanitário com dez anos de exercício na função:

Uma vez, durante uma inspeção ao mercado público em dia de feira, os banheiros estavam tão sujos, mas tão sujos, que tivemos que fechar. Quando chegamos na Secretaria, já tinha uma ligação do prefeito querendo saber que absurdo era aquele. Mandou abrir todos. Isso dá uma revolta na gente!

No que tange aos ganhos salariais, houve unanimidade sobre a atividade ser mal remunerada. Outro aspecto relatado diz respeito à desatualização do Código Sanitário (66\%). Entretanto, a maioria dos trabalhadores $(75 \%)$ apontou situações em que eles se sentiam gratificados com o resultado da sua atuação:

Se pelos menos a gente tivesse fotografado o bar do Josias, para mostrar o antes e o depois... Nosso trabalho não é só punir, a gente aqui tem que ter muito jeito, saber conversar... Não adianta ir com grosseria. Só a gente que conheceu o bar do Josias antes e depois de uns trinta dias que fomos lá, a mudança que ele fez. Tudo direitinho como a gente ensinou (agente sanitário, dez anos na função).

Os trabalhadores da vigilância epidemiológica informaram menor número de dificuldades, dentre as quais se destacaram: falta de transporte exclusivo (33\%); falta de investimento em treinamentos (100\%); dados incompletos nas fichas de investigação $(100 \%)$; e endereços incompletos nas fichas e sem ponto de referência (50\%). Todos os trabalhadores entrevistados referiram dificuldades pedagógicas: "Sinto dificuldade às vezes de abordar a 
comunidade, é muito difícil" (agente de vigilância epidemiológica, oito anos na função).

Majoritariamente, as falas de trabalhadores e gestores destacaram que há empenho no desenvolvimento das atividades, mas as dificuldades e necessidades de aprendizagem que os trabalhadores conseguiram expressar consolidam a importância da formação técnica. Confirma-se, então, que quando eles não têm acesso a processos formativos cidadãos são transformados em cumpridores de ordens, normas e regras determinadas por outros atores, o que leva a uma divisão intelectual e de classe social (Brasil, 2005).

Ao serem interrogados sobre as causas das dificuldades enfrentadas, solicitou-se que os gestores as pontuassem por ordem de importância. Após 'insatisfação salarial', a segunda maior causa de dificuldade segundo os gestores referiu-se ao desempenho técnico dos trabalhadores. Contudo, mudanças significativas nesse desempenho são improváveis, caso não se transforme a gestão e sem que se qualifiquem e valorizem esses trabalhadores, que são os responsáveis pela execução dessas políticas.

Ao mesmo tempo que manifestaram grande esperança de transformação a partir de uma formação de nível médio idealizada, o desempenho dos sujeitos do estudo parece ser avaliado tanto mais negativamente quanto menor o tempo na função de gestão, o que se depreende das seguintes falas dos gestores e coordenadores, aqui designados genericamente como gestores:

\footnotetext{
"Não compreendem o processo de trabalho"; "Alguns não respeitam a hierarquia das funções"; "Não acompanham os indicadores pactuados"; "São indisciplinados no trabalho"; "Deveria haver mais compromisso com o trabalho como um todo"; "Não têm habilidade ao lidar com a população" (gestores com até dois anos na função).

"Não têm alcance da importância do trabalho deles"; "Eles atrasam o envio de dados para a Secretaria Estadual"; "Iniciam as atividades e demoram a terminar"; "Não acompanham os indicadores pactuados"; "Não têm habilidade ao lidar com a população" (gestores com quatro a seis anos na função).
}

Observou-se um tensionamento entre as falas dos trabalhadores e as dos gestores, consubstanciado nos seguintes pontos: 1) Constatou-se a deficiência de transporte para o trabalho de campo e que alguns trabalhadores usam seu próprio meio de transporte (bicicletas, motos) - como alguns chefes podem afirmar, então, que esses trabalhadores não têm compromisso ou não estão preocupados em cumprir as suas atividades? 2) Alguns trabalhadores não receberam sequer a capacitação curta e pontual referida pelos demais - como pode a gestão esperar que eles entendam o processo de trabalho e conheçam a importância da sua função? 3) Em Alagoas, não se ofereceu formação es- 
pecífica em vigilância - como esperar que se inscrevam candidatos com essa formação nos concursos? 4) Em alguns municípios, apenas os coordenadores das vigilâncias têm acesso a computador com internet, e não há reuniões para avaliação e planejamento - como os trabalhadores podem ter acesso às informações de uma forma global?

Interrogados sobre o financiamento das ações, quatro representantes dos gestores não souberam informar, no ato da entrevista, qual a fonte de financiamento das vigilâncias, o que parece indicar que nas equipes de gestão também se observam dificuldades no processo de trabalho.

\section{Considerações finais}

O estudo sinaliza desafios para que a formação desse trabalhador seja um fator determinante na mudança de seu processo de trabalho. Supunha-se ser essa força de trabalho composta majoritariamente por trabalhadores de nível médio sem formação profissional no campo das vigilâncias. Os achados mostram uma realidade ainda mais perversa, com todos os trabalhadores, independentemente de sua escolaridade, sem formação específica para o trabalho. E quanto aos que receberam alguma capacitação, esta foi ministrada na forma de treinamentos de curta duração.

A articulação e a comunicação entre os trabalhadores das vigilâncias e deles com outros da saúde ou de setores externos a ela são frutos de iniciativas pessoais para resolver problemas pontuais - assim, podem ser chamadas de articulação?

Os documentos norteadores das práticas demonstraram que esses trabalhadores executam muitas atribuições, que lhes são cobradas, mas não compreendem seu processo de trabalho. Entretanto, no setor saúde, são necessários profissionais que realizem muito mais do que atribuições e procedimentos técnicos.

Os gestores apontaram a necessidade urgente de formar trabalhadores de nível médio das vigilâncias. No entanto, as tensões observadas entre as falas dos gestores e as dos trabalhadores são pontos muito significativos, que implicam a necessidade de se instituírem mecanismos de coordenação efetiva do trabalho das equipes, no que a formação técnica somente pode ajudar, mas não resolve.

Além da formação técnica específica para as vigilâncias, é urgente revisar processos de trabalho e de gestão, para que constrangimentos institucionais não invalidem o exercício do futuro cidadão técnico das vigilâncias. Cabe refletir, na conjuntura atual, se é justo cobrar desses trabalhadores, hoje, a prática profissional idealizada na política nacional de saúde e em seus documentos oficiais. 


\section{Colaboradores}

Tânia Kátia de Araújo Mendes realizou a pesquisa, analisou os resultados e redigiu a primeira versão do artigo. Sérgio Pacheco de Oliveira e Marismary Horsth De Seta orientaram o estudo, participaram da discussão dos resultados, da redação e da revisão do artigo. Elisabete Vianna Delamarque participou da elaboração da primeira versão do artigo, bem como da sua revisão. Todos os autores aprovaram a versão final do artigo.

Resumen La descentralización de las vigilancias sanitaria, epidemiológica y ambiental para los municipios cobró fuerzas a partir de cambios en la organización y en el financiamiento federal, cuando germinó la idea de la integración entre ellas y de ellas con la atención individual y colectiva. En los organigramas de muchas secretarías de salud, las vigilancias fueron reunidas bajo una coordinación común, y los gestores solicitaron la formación de nuevos profesionales para esa disposición. Este artículo apunta a delinear los perfiles de los profesionales de nivel medio de las vigilancias de seis municipios de Alagoas, Brasil, y de los servicios en los cuales operan, agregando percepciones de los gestores sobre la práctica de esos trabajadores, que representan el $88 \%$ de la fuerza de trabajo de las vigilancias en esos municipios. Sin formación específica para realizar sus actividades, el desempeño de los trabajadores fue evaluado como peor cuanto menor el tiempo de ejercicio del gestor en el cargo. Las dificultades destacadas fueron: injerencia política en el trabajo de vigilancia sanitaria y ambiental; cumplimentación deficiente de los formularios de investigación epidemiológica por parte de los equipos de salud de la familia en los seis municipios; e indefinición del rol profesional en la vigilancia en salud del trabajador. La necesaria formación técnica es insuficiente para superar esas dificultades, necesitando la revisión de procesos de gestión y coordinación del trabajo de los equipos para lograr prácticas más efectivas.

Palabras clave educación profesional; vigilancia sanitaria; vigilancia epidemiológica; vigilancia ambiental; vigilancia en la salud.

\section{Notas}

1 Fundação Universitária de Ciências da Saúde de Alagoas, Escola Técnica de Saúde Professora Valéria Hora, Maceió, Alagoas, Brasil.

$<$ taniakatiaam@gmail.com>

Correspondência: Fundação Universitária de Ciências da Saúde de Alagoas, Escola Técnica de Saúde Professora Valéria Hora, Rua Pedro Monteiro, 347, Centro, CEP 57020-380, Maceió, Alagoas, Brasil.

2 Fundação Oswaldo Cruz, Escola Nacional de Saúde Pública Sergio Arouca, Departamento de Administração e Planejamento em Saúde, Rio de Janeiro, RJ, Brasil.

<spacheco@ensp.fiocruz.br> 
3 Fundação Oswaldo Cruz, Escola Nacional de Saúde Pública Sergio Arouca, Departamento de Administração e Planejamento em Saúde, Centro Colaborador de Vigilância Sanitária, Rio de Janeiro, RJ, Brasil.

<betedelamarque@ensp.fiocruz.br>

4 Fundação Oswaldo Cruz, Escola Nacional de Saúde Pública Sergio Arouca, Departamento de Administração e Planejamento em Saúde, Rio de Janeiro, RJ, Brasil.

$<$ deseta@ensp.fiocruz.br $>$

${ }^{5}$ Estudo de municípios selecionados do estado de Pernambuco indicou que a vigilância epidemiológica (VE) estava implantada em pouco mais de um quarto dos municípios estudados e parcialmente implantada em menos da metade $(46 \%)$, encontrando-se mais estruturada apenas nos municípios de grande porte (Carvalho et al., 2005).

${ }^{6}$ A instauração de processo administrativo sanitário representa uma aproximação ao uso efetivo do poder de polícia administrativa e ao grau de organização e formalização do trabalho, bem como à segurança jurídica das ações (Anvisa, 2013).

7 Está dito 'novamente' pois o movimento de reunião das vigilâncias sanitária e epidemiológica nos organogramas das secretarias, principalmente estaduais, ocorreu anteriormente, representando uma das três vertentes da vigilância da saúde apontadas por Teixeira, Paim e Vilasboas (1998). Contudo, a conjuntura atual é completamente diversa daquela, pois há uma política em curso expressa na direcionalidade dada pelas normas, no financiamento, nas pesquisas e na cooperação com os órgãos formadores (De Seta e Dain, 2010).

8 A Escola Técnica Professora Valéria Hora, do estado de Alagoas, atuou na formação de auxiliares e técnicos de enfermagem e de ACSs, bem como de outros trabalhadores para o cuidado direto à saúde das pessoas no SUS. Participou da qualificação básica em agentes de vigilância em saúde (Proformar). Estava em elaboração a formação do técnico em vigilância em saúde, na época do estudo, e a pesquisa aqui apresentada alicerçou essa construção. Em breve, inicia-se a formação do técnico em vigilância em saúde no Alagoas.

\section{Referências}

ABRUCIO, Fernando. L. Os barões da federação: os governadores e a redemocratização brasileira. São Paulo: Hucitec; USP, 1998.

\section{AGÊNCIA NACIONAL DE VIGILÂNCIA SA-} NITÁRIA (ANVISA). Perfil da Vigilância Sanitária Municipal no Brasil: informe preliminar. Brasília: Anvisa, 2013. Disponível em: <www6. ensp.fiocruz.br/visa/files/perfil \%20da $\% 20$ vigil \%C3\% A2ncia \% 20sanit \% C3\% Alria $\% 20$ municipal_informe \%20preliminar.pdf $>$. Acesso em: 20 jan. 2015.
BRASIL. Documentos preparatórios para $3^{a}$ Conferência Nacional de Gestão do Trabalho e da Educação na saúde: trabalhadores da saúde e a saúde de todos os brasileiros - práticas de trabalho, gestão, formação e participação. Brasília: Conselho Nacional de Saúde, 2005. Disponível em: <http://bvsms.saude.gov.br/bvs/publicacoes/ cartilha3conf_pdf.pdf>. Acesso em: 20 jan. 2013.

BRASIL. Portaria n. 3.252, de 22 de dezembro de 2009. Aprova as diretrizes para execução e financiamento das ações de vigilância em saúde 
pela União, estados, Distrito Federal e municípios e dá outras providências. Diário $O f i-$ cial da União, Brasília, DF, 23 dez. 2009b. Seção I, p. 195.

BRASIL. Portaria n. 2.437, de 7 de dezembro de 2005. Dispõe sobre a ampliação e o fortalecimento da Rede Nacional de Atenção Integral à Saúde do Trabalhador (RENAST) no Sistema Único de Saúde (SUS) e dá outras providências. Diário Oficial da União, Brasília, DF, 9 dez. 2005. Seção I, p. 78.

BRASIL. Portaria n. 2.728, de 11 de novembro de 2009. Dispõe sobre a Rede Nacional de Atenção Integral à Saúde do Trabalhador (RENAST) e dá outras providências. Diário Oficial da União, Brasília, DF, 12 nov. 2009b. Seção I, p. 76.

BRASIL. Portaria n. 870, de 16 de julho de 2008. Aprova, em extrato, o Catálogo Nacional de Cursos Técnicos de Nível Médio, elaborado pela Secretaria de Educação Profissional e Tecnológica do Ministério da Educação. Diário Oficial da União, Brasília, DF, Número 137, 18 jul. 2008, Seção 1, p. 13.

BRASIL. Portaria n. 1.378, de 9 de julho de 2013. Regulamenta as responsabilidades e define diretrizes para execução e financiamento das ações de vigilância em saúde pela União, estados, Distrito Federal e municípios, relativos ao Sistema Nacional de Vigilância em Saúde e Sistema Nacional de Vigilância Sanitária. Diário Oficial da União, Brasília, DF, 10 jul. 2013. Seção I, p. 48.

CARVALHO, Eduardo F. et al. Avaliação da vigilância epidemiológica em âmbito municipal. Revista Brasileira de Saúde Materno Infantil, Recife, v. 5, supl. 1, p. s53-s62, dez. 2005.

CZERESNIA, Dina. (org). Promoção da Saúde: conceitos, reflexões, tendências. Rio de Janeiro: Editora Fiocruz, 2003.

DE SETA, Marismary H. A construção do Sistema Nacional de Vigilância Sanitária: uma análise das relações intergovernamentais na perspectiva do federalismo. Tese (Doutorado em Saúde Coletiva.) - Instituto de
Medicina Social, Universidade do Estado do Rio de Janeiro, Rio de Janeiro, 2007.

DE SETA, Marismary H.; DAIN, Sulamis. Construção do Sistema Brasileiro de Vigilância Sanitária: argumentos para debate. Ciência \& Saúde Coletiva, Rio de Janeiro, v. 15, n. 3, p. 3.307-3.317, nov. 2010.

DE SETA, Marismary H.; REIS, Lenice G. C. Construção, estruturação e gestão das vigilâncias do campo da saúde. In: GONDIM, Roberta.; GRABOIS, Victor.; MENDES JUNIOR, Walter. V. (orgs.). Qualificação dos gestores do SUS. 2. ed. Rio de Janeiro: Fiocruz/ Ensp/EAD, 2011. p. 239-276. Disponível em: $<$ www4.ensp.fiocruz.br/biblioteca/home/ exibedetalhesBiblioteca.cfm?ID $=12564 \&$ Tipo=B $>$. Acesso em: 20 jun. 2013.

DE SETA, Marismary H.; REIS, Lenice G. C.; PEPE, Vera Lúcia E. Vigilâncias do campo da saúde: conceitos fundamentais e processos de trabalho. In: GONDIM, Roberta.; GRABOIS, Victor.; MENDES JUNIOR, Walter V. (orgs.). Qualificação dos gestores do SUS. 2. ed. Rio de Janeiro: Fiocruz/Ensp/EAD, 2011. p. 199-237. Disponível em: <www4.ensp. fiocruz.br/biblioteca/home/exibedetalhes Biblioteca. $\mathrm{cfm} ? \mathrm{ID}=12562 \&$ Tipo $=\mathrm{B}>$. Acesso em: 20 jun. 2013.

GALDINO, Adriana; SANTANA, Vilma S.; FERRITE, Silvia. Os Centros de Referência em Saúde do Trabalhador e a notificação de acidentes de trabalho no Brasil. Cadernos de Saúde Pública, Rio de Janeiro, v. 28, n. 1, p. 145-159, jan. 2012.

FERRARI, Helena Y. M. Descentralização da vigilância: uma análise dos serviços no contexto da municipalidade, microrregião Teles Pires, Mato Grosso, Brasil. Dissertação (Mestrado Profissional em Saúde Pública) - Escola Nacional de Saúde Pública Sergio Arouca, Fundação Oswaldo Cruz, Rio de Janeiro, 2010.

LEÃO, Luís H. C.; CASTRO, Alexandre C. Políticas públicas de saúde do trabalhador: análise da implantação de dispositivos de institucionalização em uma cidade brasileira. Ciência \& Saúde Coletiva, Rio de Janeiro, v. 18, n. 3, p. 769-778, mar. 2013. 
MACHADO, Jorge M. H. et al. Situação da Rede Nacional de Atenção Integral em Saúde do Trabalhador (Renast) no Brasil, 2008-2009. Revista Brasileira de Saúde Ocupacional, São Paulo, v. 38, n. 128, p. 243-256, 2013.
TEIXEIRA, Carmen. F.; PAIM, Jairnilson S.; VILASBOAS, Ana L. SUS, modelos assistenciais e vigilância da saúde. Informe Epidemiológico do SUS, Brasília, v. 7, n. 2, p. 7-28, abr.-jun. 1998.

Recebido em 13/11/2013

Aprovado em 21/07/2014 